\title{
Population structures among epiphytal foraminiferal communities, Nevis, West Indies
}

\author{
BRENT WILSON \\ Petroleum Geoscience Programme, Department of Chemical Engineering, The University of the West Indies, St. Augustine, Trinidad and \\ Tobago, West Indies (e-mail: bwilson@eng.uwi.tt)
}

\begin{abstract}
The taxocene of live epiphytal foraminifera was for one year monitored monthly on six phytal substrates in shallow water $(<1 \mathrm{~m})$ in two bays around Nevis, NE Caribbean Sea. Mosquito Bay was subject to a nutrient flux from a leaking septic tank. Long Haul Bay was comparatively undeveloped. SHE Community Structure Investigations (SHECSIs) revealed that the populations on five plants had logarithmic series distributions of species abundances, the slopes of $\ln S$ vs. $\ln E$ for these five time-series being within $-1 \pm 0.3$. In three time-series, they were within $-1 \pm 0.05$.

Cluster analysis of twenty-five sediment samples in shallow water $(<3 \mathrm{~m})$ indicates that Nevis is largely surrounded by a single thanatacoenosis, for which SHECSI indicates a logarithmic series population structure. However, it is not possible to reconstruct perfectly the epiphytal population from the sediment thanatacoenosis. The thanatacoenosis included 40\% allochthonous Amphistegina gibbosa, Archaias angulatus and Asterigerina carinata, washed in from offshore reefs, and few planorbulinids, although the latter dominates the biocoenosis on seagrass leaves in the backreef. J. Micropalaeontol. 27(1): 63-73, May 2008.
\end{abstract}

KEYWORDS: Thalassia, Syringodium, Caribbean, SHE Analysis

\section{INTRODUCTION}

It is axiomatic in ecology that in any multi-species population some species will be common and others rare (Magurran, 1988; Buzas \& Hayek, 2005). The extent to which a community is dominated by a few species, or, conversely, the degree to which species abundances are distributed equitably, is termed the population structure (Hayek \& Buzas, 1997). Although foraminifera have been studied for several centuries, relatively little is known about their population structures (Buzas, 2004). In particular, little is known about population structures in epiphytal foraminifera.

The Caribbean region is ideal for investigating population structures among epiphytal foraminiferal communities. Most shallow-water foraminifera in the oligotrophic Caribbean Sea are epiphytal (Cushman, 1922a; Brasier, 1975; Wilson, 1998, 2000), living on (a) the calcareous algae Penicillus capitatus, Halimeda spp. and Dasycladus vermicularis, and (b) the seagrasses Thalassia testinudum and Syringodium filiforme (Waszczak \& Steinker, 1978). On seagrasses they inhabit (a) leaves and (b) exposed rhizomes and leaf bosses, which can bear distinctly different communities (Langer, 1993; Ribes et al., 2000). Wilson (1998) found that, within the same square metre, even the leaves of $T$. testinudum and $S$. filiforme bear different assemblages. Assemblages in sediment in which the plants are rooted comprise primarily dead specimens washed from plants (Steinker \& Clem, 1984). However, much information is lost during the transition from the epiphytal biocoenosis to the sediment thanatacoenosis (Martin \& Wright, 1988). This paper compares population structures of the foraminiferal biocoenses on phytal substrates with that of the thanatacoenosis in the associated sediment, and determines the extent to which knowledge of the population structure of the epiphytal assemblages helps in the interpretation of fossil sediment assemblages.

The dataset used herein was first reported by Wilson (2000), who examined shallow-water $(<1 \mathrm{~m})$ epiphytal foraminifera communities in two embayments around the island of Nevis, northern Lesser Antilles $\left(17^{\circ} 10^{\prime} \mathrm{N}, 62^{\circ} 35^{\prime} \mathrm{W}\right.$, Fig. 1), monitoring populations monthly for twelve months to produce timeseries for populations on various plants. From Long Haul Bay (LHB, Fig. 2), a backreef bay on the northeast, windward coast, Wilson (2000) sampled populations on P. capitatus capitulae (heads), T. testinudum leaves and $T$. testinudum rhizomes and leaf bosses. From Mosquito Bay (MB), an open embayment on the northwest, leeward coast, he sampled foraminifera on $P$. capitatus capitulae, Halimeda opuntia and $S$. filiforme rhizomes and leaf bosses. At the time of sampling, MB was subject to an organic flux from a leaking septic tank.

Having calculated population densities, Wilson (2000) used time-series analysis (see Berryman, 1999) to analyse species' population dynamics on the different substrates. No evidence of seasonality was found (cf. Wilson \& Dawe, 2006) and only one, poor example of periodicity (Discorbis rosea on T. testinudum leaves). However, it was found that in LHB the total foraminiferal community on each substrate, and the populations of dominant species, typically showed stationarity - i.e. their population densities fluctuated around a constant mean, linear regression not revealing any significant long-term trends. In contrast, in $\mathrm{MB}$ the overall community and populations of dominant species showed nonstationarity, per month population densities decreasing significantly over the year of sampling. Wilson (2000) ascribed the different population dynamics to the impact of the focused organic flux in MB. Shallow-water foraminifera respond quickly to an increased nutrient flux (Altenbach, 1992), which can affect the species composition of the community (Scott et al., 2001; Hallock et al., 2003).

Given the wealth of information that can be derived from Wilson's (2000) time-series of epiphytal foraminiferal populations in MB and LHB, they have been further analysed and examined in two papers. Wilson (2006c) found that the epiphytal population comprises a collection of taxonomic guilds sensu Jaksic (1981), a guild being a group of species that exploit the same class of environmental resources in a similar way (see 


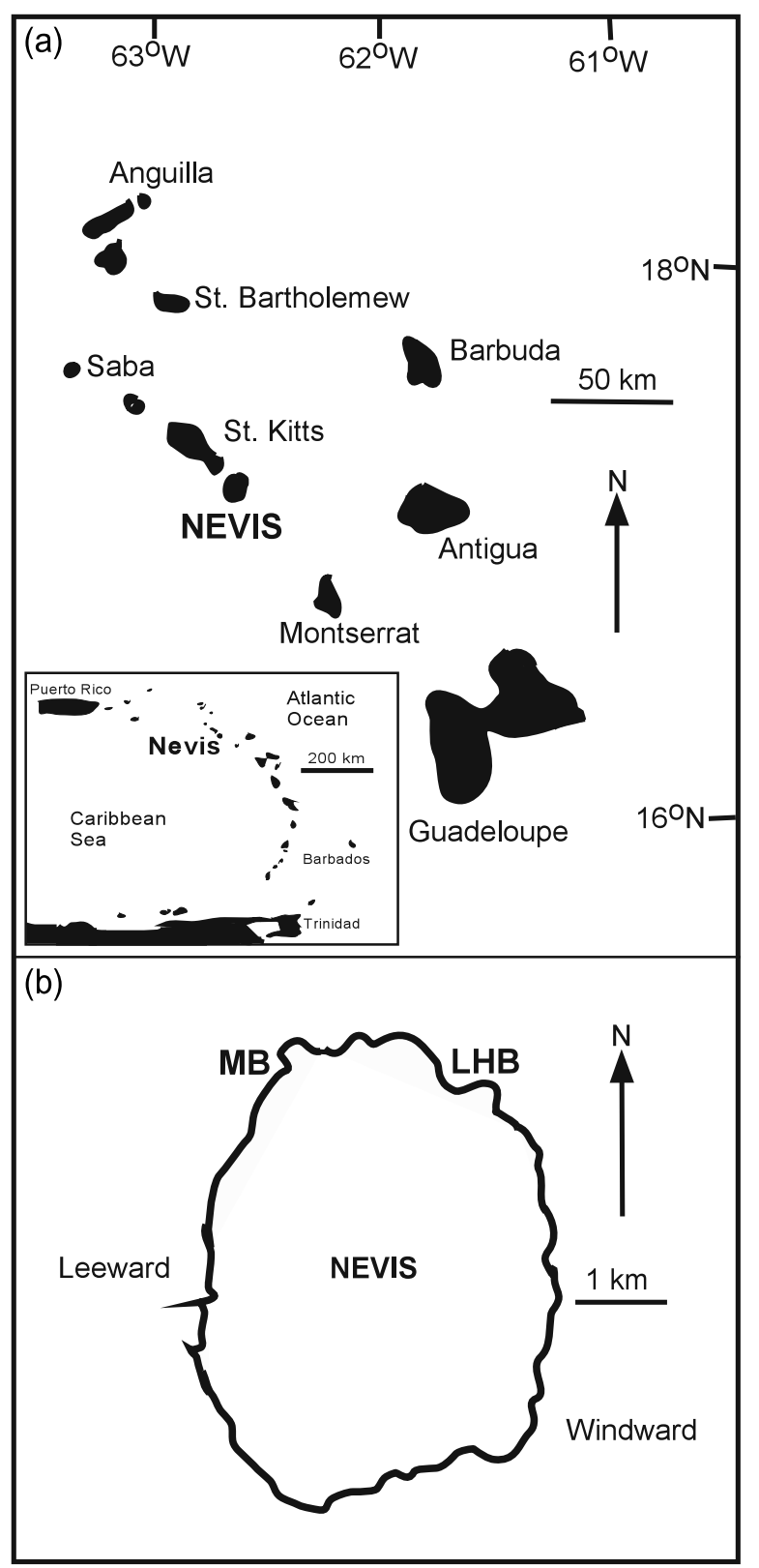

Fig. 1. (a) The northern Lesser Antilles, showing the location of Nevis. Inset: the Eastern Caribbean, indicating Nevis at the northern end of the Lesser Antilles island arc. (b) Nevis, showing the sample sites at Long Haul Bay (LHB) and Mosquito Bay (MB).

Root, 1967). Wilson \& Ramsook (2007) published the entire data set of Wilson's (2000) six time-series, and found that foraminiferal population densities on $P$. capitatus capitulae were three times higher in both bays than those on either H. opuntia or on exposed seagrass (S. filiforme, T. testinudum) rhizomes and basal leaf bosses. Mean population densities on P. capitatus capitulae were statistically indistinguishable in both bays. Thus, while the input of organic matter into MB has apparently affected the composition and population dynamics of the biocoenosis there, it has not affected the mean population densities there. Wilson \& Ramsook (2007) concluded that $P$. capitatus, which has a lifespan of $c .45$ days and supports denser

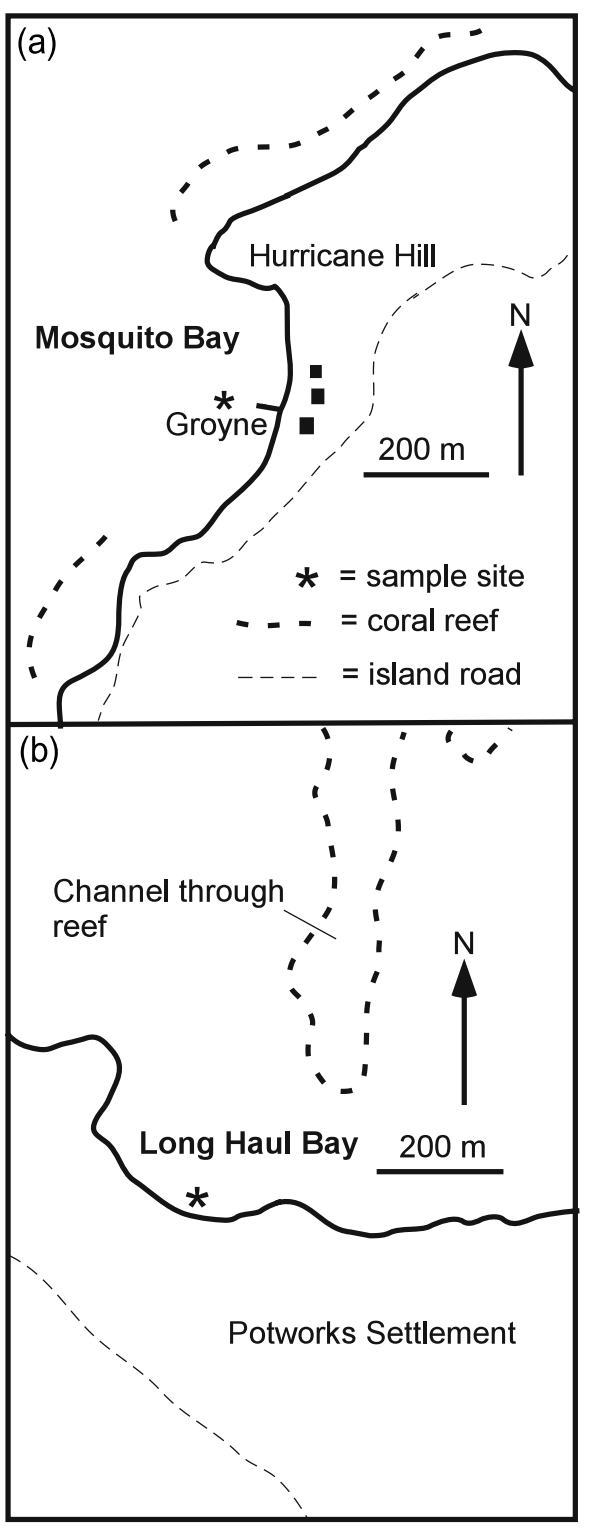

Fig. 2. Sketch maps of Long Haul Bay and Mosquito Bay, showing sites from which epiphytal samples were collected.

populations, contributes proportionally more foraminiferal tests to the sediment than do seagrass rhizomes, which support lower density populations and have life spans of several years. They suggested $P$. capitatus capitulae to support a permanently pioneering foraminiferal community that includes opportunists (Guild II of Wilson, 2006c), and seagrass rhizomes to be occupied by a climax community.

\section{SHECSI ANALYSIS: AN OUTLINE}

A taxocene is a taxonomically related set of species within a community, such as birds, gastropods or foraminifera (see Hutchinson, 1976). Many micropalaeontologists study the foraminiferal taxocene only. Therefore, knowledge of interactions between foraminifera and other taxa is slim at present. However, Magurran $(1988,2003)$ documented that, despite the possibility of interactions with other taxa, taxocenes have four 
types of community structure, no matter what organisms are examined: geometric series, logarithmic series, logarithmic normal and broken stick. These form a series from least- to most-equitable species abundance distributions.

Hayek \& Buzas (1997) determined that biological species richness $S$, diversity (measured using the information function $H=-\Sigma p_{i} \ln p_{i}$, where $p_{i}$ is the proportional abundance of the $i$ th species) and evenness (calculated from the equitability index $E=e^{H} / S$ ) are related through the decomposition formula

$$
H=\ln S+\ln E
$$

From this they developed SHE Analysis, one part of which uses cumulative population census figures, rather than a single vector of species' abundances, to determine the population structure (see also Buzas, 2004). Hayek \& Buzas (1997) introduced the term SHE Analysis for Community Structure Identification (SHECSI) to describe that aspect of SHE Analysis that determines the population structure. In SHECSI the behaviour of accumulated values of $\ln S, \ln E$ and $H$ when regressed linearly against the cumulative values of $\ln N$ (i.e. the logarithm of the cumulative number of specimens), and the expected asymptotic values of the information function $E(H)$, reveal three of the four common community structures.

- For the logarithmic series distribution $E(H)=\ln \alpha+0.58$, where $a$ is the Fisher diversity index. For this series, $H$ is constant. For a perfect logarithmic series, regression of $\ln S$ vs. $\ln E$ has a slope of -1 and an intercept of $H$.

- For the logarithmic normal distribution $E(H)=\left(1-\gamma^{2}\right) \ln S$, where $\left(1-\gamma^{2}\right)=1+\ln E / \ln S$ and $\ln E / \ln S$ is constant.

- For the broken stick distribution, $E(H)=\ln S-0.42$ and $E$ is constant at 0.66 .

Thus, $H, \ln E$ and $\ln E / \ln S$ are each constant for a different species abundance distribution. Buzas \& Hayek (2005) suggested that because of its simplicity, the constancy of the related indices and the regression formulation of $\ln S$ vs. $\ln E$, the logarithmic series should be the null model for the investigation of population structure. Buzas (2004) used logarithmic series relationships when investigating the community structure of foraminiferal assemblages in two Miocene beds in Maryland.

SHECSI is used here to determine community structures in the foraminiferal taxocene on phytal substrates in LHB and MB, Nevis, using the full dataset presented in Wilson \& Ramsook (2007) and employing the logarithmic series as the null model.

\section{MATERIALS AND METHODS}

The geography and climate of the $50 \mathrm{~km}^{2}$ volcanic island of Nevis are described thoroughly in Wilson (2006c) and Wilson \& Ramsook (2007). At the time of sampling, both LHB and MB supported seagrass meadows and calcareous algae, but the vegetation in LHB was lusher, comprising a seagrass climax community of primarily $T$. testinudum. The seagrass meadow in MB comprised a pioneering community of primarily S. filiforme (details of seagrass ecology from Zieman \& Zieman, 1989).

Samples were collected during 1994-1995 on the Thursday of the third week of each calendar month, and comprised sedimenttrapping algae, seagrass rhizomes sensu Langer (1993) and seagrass leaves. When rough seas suspended sediments and rendered the water cloudy, sampling was restricted to substrates that could be located and identified by touch. Cloudy water occurred more frequently in MB than in LHB.

From LHB P. capitatus capitulae were collected c. $10 \mathrm{~m}$ from shore within a seagrass meadow adjacent to a patch reef. Thalassia testinudum rhizomes and basal leaf bosses (leaves removed), and separate samples of $T$. testinudum leaves, were collected along the steep, shoreward edge of the meadow, all at c. $1 \mathrm{~m}$ depth.

Three substrates were sampled in MB: H. opuntia from a gabion at $30 \mathrm{~cm}$ depth at the bay head, and $P$. capitatus heads (capitulae) and exposed S. filiforme rhizomes and basal leaf bosses (leaves removed) from an area $c .200 \mathrm{~m}^{2}$ and $1 \mathrm{~m}$ deep immediately seaward of the gabion. The gabion was destroyed when Hurricanes Luis and Marilyn struck in September 1995.

Sampling involved combining material from several individual plants to form 'pseudoreplicates' sensu Hurlbert (1984). All samples of $P$. capitatus comprised ten capitulae, and seagrass leaves of approximately 100 leaves.

The six samples collected each month (three each from MB and LHB) were stained by soaking for 24 hours in a solution of $70 \%$ isopropyl alcohol (the only preservative readily available on Nevis) and $2 \mathrm{~g} \mathrm{l}^{-1}$ rose Bengal. Rose Bengal stains those tests containing protoplasm (Walton, 1952).

The foraminiferal community on the leaves of seagrasses included many firmly attached planorbulinids. This substrate had to be prepared in a different way to the others, on which planorbulinids were rare. The preparation technique, described by Wilson (1998), entails drying the leaves until they crumble, then sieving them over a $125 \mu \mathrm{m}$ mesh to remove fine particles. Stained foraminifera are picked from the $>125 \mu \mathrm{m}$ fraction.

Specimens were removed from the remaining five plant substrates by washing them under running water over a $63 \mu \mathrm{m}$ mesh. The washed plants were examined for evidence of permanently attached foraminifera still in place. Few were found. The detached foraminifera were dried at $c .100^{\circ} \mathrm{C}$ and sieved over a $125 \mu \mathrm{m}$ mesh. Stained specimens were picked from the $>125 \mu \mathrm{m}$ fraction, and the per sample numbers of specimens $N$ recorded.

The specimens were sorted into species, identified using d' Orbigny (1839), Cushman (1918, 1921, 1922a, b, 1923, 1929, 1930, 1931) and Schnitker (1971), and the number of specimens per species per sample counted. Population diversity, measured using both species richness $S$ and the information function $H$, and dominance, measured using the Equitability Function $E$, were calculated for accumulated values of $N$ over all samples for each substrate. Linear regression of $\ln S, H$ and $\ln E$ was conducted against $\ln N$, and goodness of fit determined using Pearson's product moment correlations. Regression of $\ln S$ vs. $\ln E$ was also conducted.

\section{RESULTS}

The accumulated values of $N, S, H$ and $E$ for each plant substrate in Long Haul Bay and Mosquito Bay are given in Tables 1 and 2, respectively, which also show the mean values of accumulated $H(=\hat{H})$. In Figures $3 \mathrm{a}-\mathrm{c}(\mathrm{LHB})$ and $4 \mathrm{a}-\mathrm{c}(\mathrm{MB})$ the accumulated values of $\ln S, H$ and $\ln E$ are graphed against accumulated $\ln N$. Results for the two bays are presented separately. 


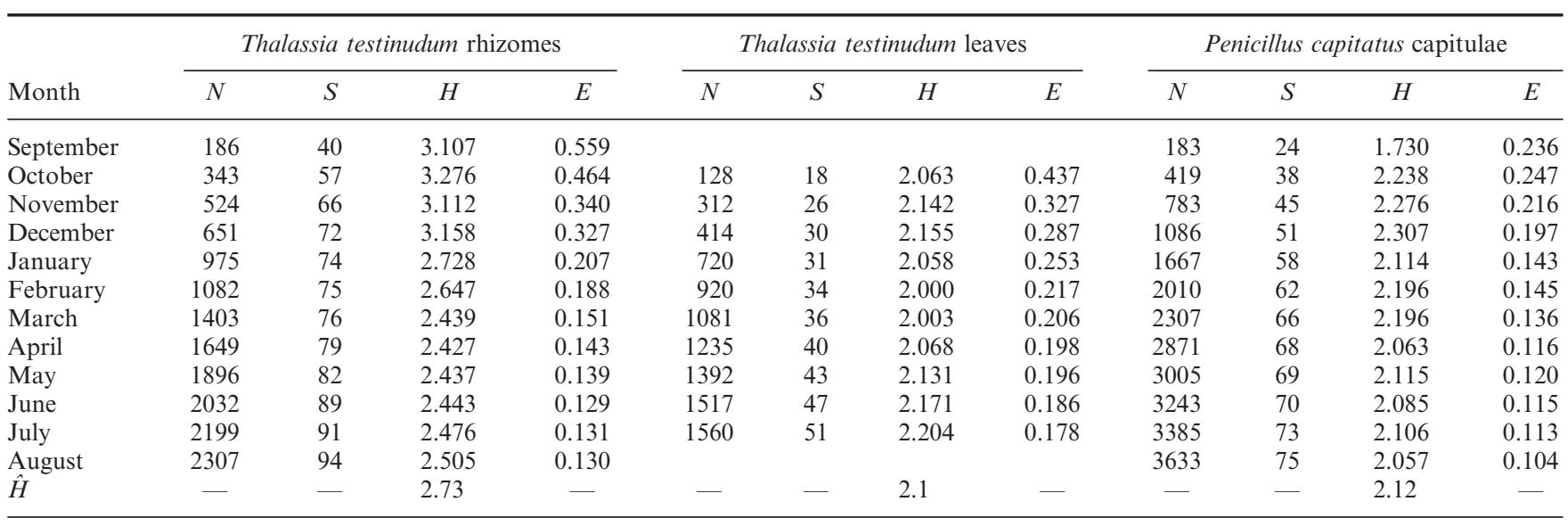

$N$, cumulative number of specimens; $\mathrm{S}$, biological species richness; $H$, diversity; $E$, evenness.

Table 1. Accumulated values of $N, S, H$ and $E$ for each plant substrate in Long Haul Bay and the mean value of accumulated $H$ (= $\hat{H}$ )

\section{Long Haul Bay}

Thalassia roots. Examination of $H$ (range 2.427-3.107) indicates that on this substrate it reaches a constant of c. 2.454 above $N=1400$. Hayek \& Buzas (1997, table 14.2, fig. 14.2) found a similar convergence on a constant among forest trees in Bolivia, and limited their subsequent analysis to those samples beyond which $H$ first attained its constant value. When this procedure is followed, analysis being restricted to the final six measurements in the $T$. testinudum time-series, $H$ is almost constant $(H=1.56+0.119 \times \ln N, \quad r=0.745)$, the correlation between accumulated $H$ and $\ln N$ not being significant at the $95 \%$ confidence level $(p=0.089)$. As $\ln S$ vs. $\ln N$ increases $(\ln S=1.131+0.439 \times \ln N, r=0.968, p=0.002) \ln E$ vs. $\ln N$ decreases $(\ln E=0.438-0.322 \times \ln N, r=0.955, p=0.003)$. Linear regression of $\ln S$ vs. $\ln E$, which for a $\operatorname{logarithmic}$ series would give an intercept of final accumulated $H$ (i.e. 2.505) and a slope of -1 , actually gives an intercept of 1.88 and a slope of -1.29 . These data are not a perfect fit for a logarithmic series model. However, the constant value of cumulative $H$ above the asymptote at $N=1400$, and the behaviour of $\ln N$ vs. $\ln S$ and $\ln E$, are concluded to indicate a logarithmic series distribution of species abundances in this population.

Thalassia leaves. The accumulated values of $H$ fluctuate between 2.0 and 2.31 , but oscillate around a constant when regressed against $\ln N$ (slope $-0.0306, r=0.257, p=0.473$ ), whereas $\ln S$ vs. $\ln N$ increases (slope $=0.363, r=0.970, p<0.005$ ) and $\ln E$ vs. $\ln N$ decreases (slope $-0.333, r=0.970, p<0.005$ ). These last two regressions, although of opposite sign, differ only by 0.03 . Regression of $\ln S$ vs. $\ln E$ gives $\ln S=2.066-1.036 \times \ln E$, the slope of which is almost -1 , and the intercept of which is close to the final accumulated value of $H(2.20)$ and the value of $\hat{H}=2.12$. For $N=1560$ and $S=51, a=10.1$, so that for a logarithmic series distribution $E(H)=2.89$. Although $E(H)$ exceeds the final value of $H$ by 0.69 , the foraminiferal population structure on Thalassia leaves in LHB is concluded to be a logarithmic series.

Penicillus capitatus. Cumulative values of $H$ have a wide spread (minimum 1.73, maximum 2.31). However, when regressed

\begin{tabular}{|c|c|c|c|c|c|c|c|c|c|c|c|c|}
\hline \multirow[b]{2}{*}{ Month } & \multicolumn{4}{|c|}{ Halimeda opuntia } & \multicolumn{4}{|c|}{ Penicillus capitatus capitulae } & \multicolumn{4}{|c|}{ Syringodium filiforme rhizomes } \\
\hline & $N$ & $S$ & $H$ & $E$ & $N$ & $S$ & $H$ & $E$ & $N$ & $S$ & $H$ & $E$ \\
\hline September & & & & & 164 & 27 & 2.500 & 0.451 & & & & \\
\hline October & 158 & 53 & 3.289 & 0.624 & 291 & 45 & 2.990 & 0.442 & 63 & 28 & 3.087 & 0.783 \\
\hline November & 418 & 54 & 3.447 & 0.581 & 397 & 51 & 2.847 & 0.338 & 119 & 40 & 3.337 & 0.703 \\
\hline December & 552 & 58 & 3.371 & 0.502 & & & & & & & & \\
\hline January & 789 & 67 & 3.352 & 0.426 & 525 & 57 & 2.947 & 0.334 & & & & \\
\hline February & 951 & 70 & 3.329 & 0.399 & 771 & 61 & 2.735 & 0.253 & 258 & 53 & 3.365 & 0.546 \\
\hline March & 1190 & 77 & 3.323 & 0.360 & 1051 & 65 & 2.664 & 0.221 & 391 & 65 & 3.528 & 0.524 \\
\hline April & 1329 & 79 & 3.322 & 0.351 & 1178 & 68 & 2.733 & 0.226 & 488 & 69 & 3.517 & 0.488 \\
\hline May & 1452 & 83 & 3.367 & 0.349 & 1239 & 69 & 2.756 & 0.228 & 619 & 76 & 3.546 & 0.456 \\
\hline June & 1574 & 86 & 3.382 & 0.342 & 1426 & 73 & 2.794 & 0.224 & 722 & 82 & 3.615 & 0.470 \\
\hline July & 1734 & 88 & 3.338 & 0.320 & 1604 & 79 & 2.838 & 0.216 & 964 & 94 & 3.670 & 0.418 \\
\hline August & 1894 & 91 & 3.361 & 0.317 & & & & & & & & \\
\hline$\hat{\mathrm{H}}$ & - & - & 3.35 & - & - & - & 2.78 & - & - & - & 3.46 & - \\
\hline
\end{tabular}

$N$, cumulative number of specimens; $\mathrm{S}$, biological species richness; $H$, diversity; $E$, evenness.

Table 2. Accumulated values of $N, S, H$ and $E$ for each plant substrate in Mosquito Bay and the mean value of accumulated $H(=\hat{H})$ 

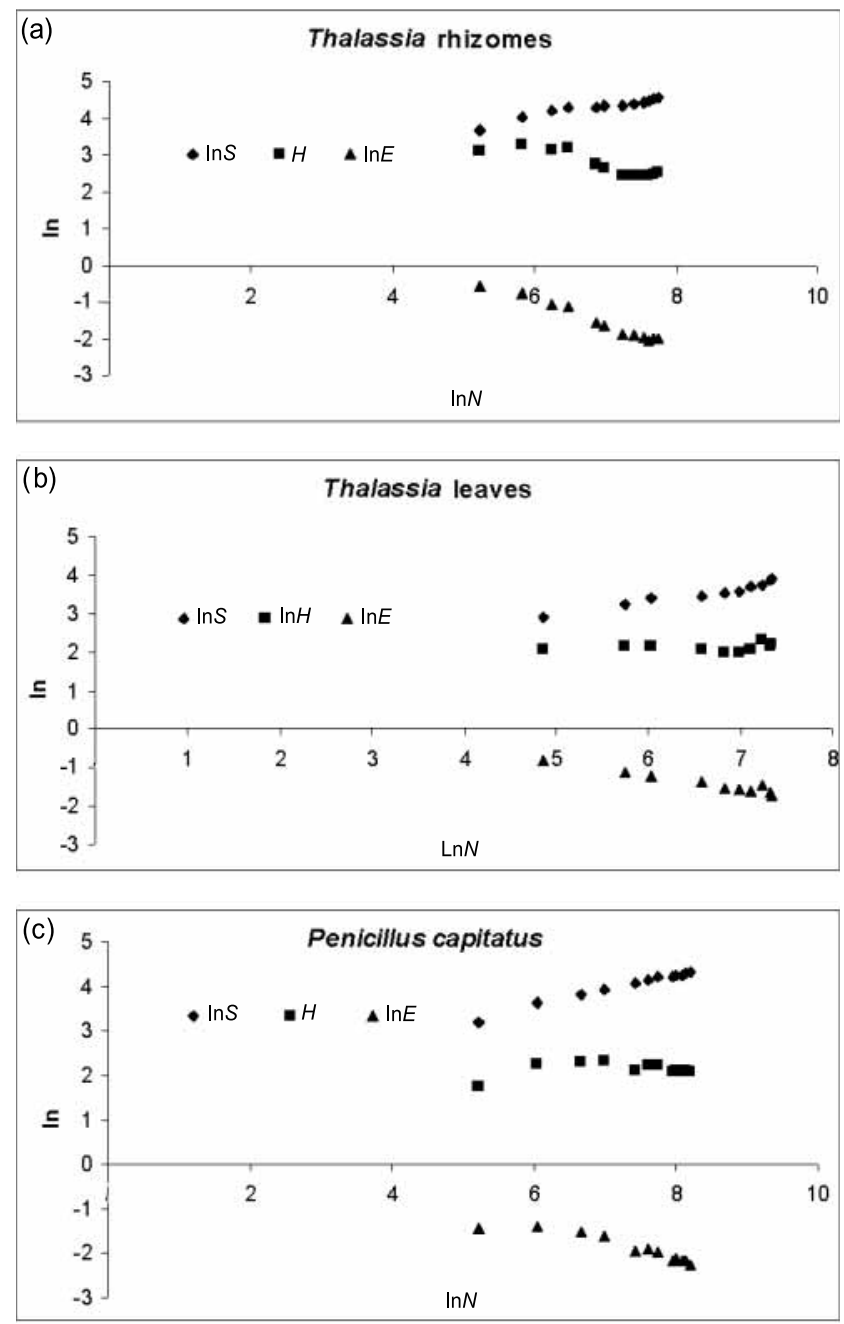

Fig. 3. Graphs of $\ln S, H$ and $\ln E$ against cumulative $\ln N$ for epiphytal foraminifera on substrates in Long Haul Bay.

against $\ln N$, they fluctuate around a constant (slope -0.0374 , $r=0.275, p=0.386$ ), whereas $\ln S$ vs. $\ln N$ increases (slope $=$ $0.354, r=0.992, p<0.005$ ) and $\ln E$ vs. $\ln N$ decreases (slope $-0.312, r=0.914, p<0.005)$. The slopes of these last two regressions are opposite in sign but almost equal (difference $=0.042$ ). Regression of $\ln S$ vs. $\ln E$ gives $\ln S=2.183-0.968 \times \ln E$, the slope of which is almost -1 , and the intercept of which is close to the final accumulated value of $H(2.06)$. The value of $\hat{H}$ was 2.12. For $N=3633$ and $S=75, a=13.37$, and the expected final $H$ for a logarithmic series is $E(H)=\ln 13.37+0.58=3.17$. Although $E(H)$ exceeds the final value of accumulated $H$ by 1.11 , the foraminiferal population on $P$. capitatus in LHB is, from these data, concluded to have a logarithmic series distribution.

\section{Mosquito Bay}

Halimeda opuntia. Regression of $H$ against $\ln N$ indicates that, on $H$. opuntia, $H$ fluctuates around a constant (slope=0.005). However, Pearson's product moment correlation shows only a poor and statistically insignificant fit between observed and expected values $(r=0.09, p=0.79)$, indicating that values of $H$ fluctuate as samples are progressively accumulated (maximum
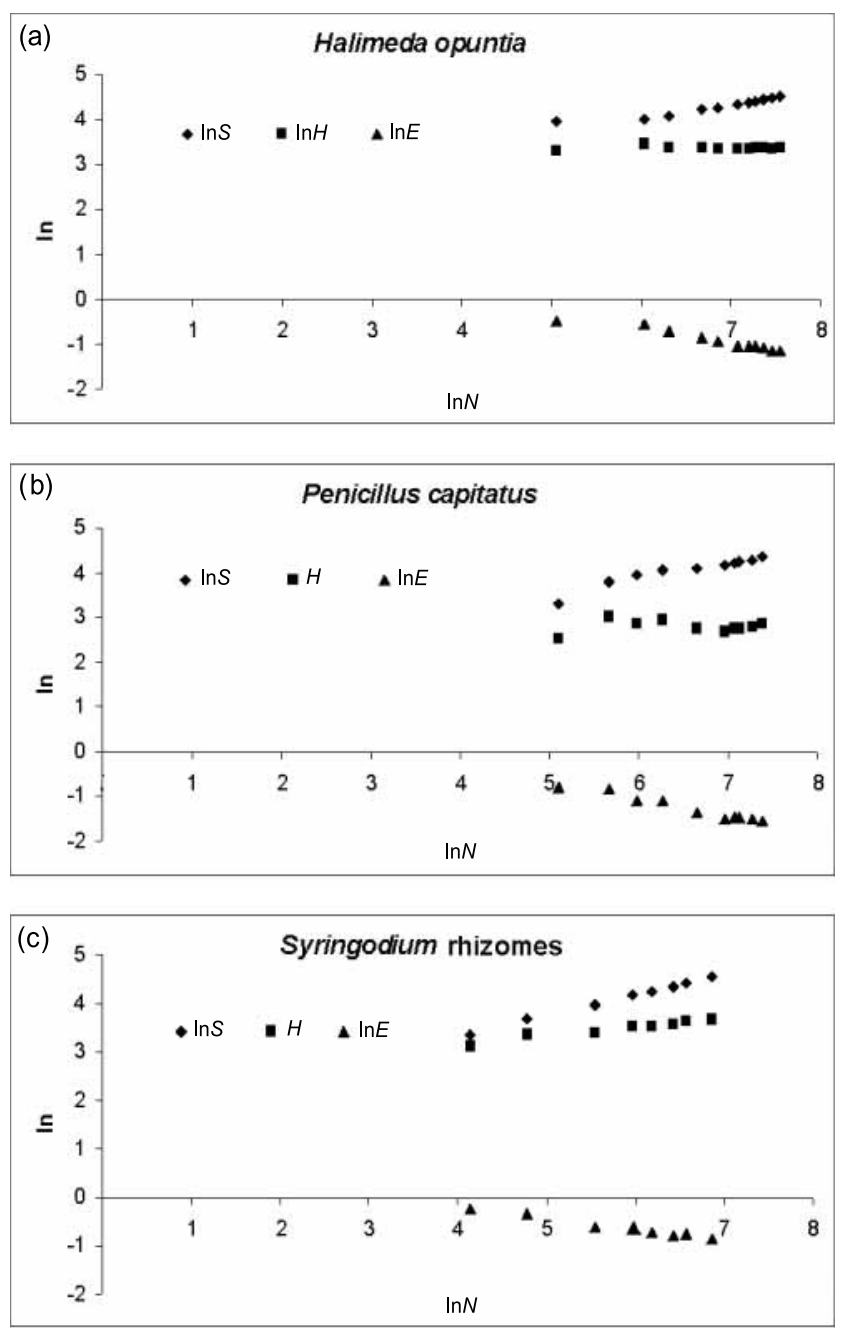

Fig. 4. Graphs of $\ln S, H$ and $\ln E$ against cumulative $\ln N$ for epiphytal foraminifera on substrates in Mosquito Bay.

$H=3.45$, minimum $H=3.29$ ). In contrast, there are good fits when both $\ln S$ and $\ln E$ are regressed against $\ln N(\ln S$, slope $=0.25, r=0.94, p<0.005 ; \ln E$, slope $=0.31, r=0.97, p<0.005)$. The slopes of these regressions are opposite in sign and almost equal. The last observed value of $H$ in the accumulated series is 3.36, while $\hat{H}=3.35$. Regression of $\ln S$ against $\ln E$ for the $H$. opuntia community gives an intercept of 3.54 , and a slope -0.82 $(r=0.98, p<0.005)$. Given $N=1894$ and $S=91, \alpha=21.96$. Thus, the expected final $H$ is $E(H)=\ln 21.96+0.58=3.67$. Although not a perfect fit, these results, and especially the fluctuation of $H$ around an almost constant value, are concluded to indicate a logarithmic series distribution.

Penicillis capitatus. Cumulative $H$ on this substrate varies between 2.5 and 3.0. Regression of $H, \ln S$ and $\ln E$ against $\ln N$ indicates that cumulative $H$, although it fluctuates, does so around a constant (slope $=0.0199, r=0.108, p=0.77$ ), whereas $\ln S$ increases (slope $=0.393, r=0.958, p<0.005$ ) and $\ln E$ decreases (slope $=-0.373, r=0.972, p<0.005$ ). That the slopes of $\ln S$ and $\operatorname{lnE}$ are almost equal (difference 0.02) but opposite in sign is indicative of a logarithmic series distribution. The last observed 
value of accumulated $H$ is 2.84 , while $\hat{H}=2.78$. Regression of $\ln S$ vs. $\ln E$ for the MB $P$. capitatus fauna gives an intercept of 2.83 and a slope of $-0.958(p=0.0005)$. For $N=1604$ and $S=79$, $a=17.43$. Given these values, the expected final $H$ for a logarithmic series is $E(H)=\ln 17.43+0.58=3.44$. Despite the 0.6 difference between $E(H)$ and final $H$, this population is concluded to have a logarithmic series structure.

Syringodium filiforme. It is not possible to discriminate the community structure on this substrate unequivocally. The accumulated values of $H, S$ and $E$ are not constant. Regression of $H$, $\ln S$ and $\ln E$ against $\ln N$ shows that both $H$ (slope $=0.194$, $r=0.97, p<0.005)$ and $\ln S$ (slope $=0.429, \mathrm{r}=0.99, p<0.005)$ increase with increasing $\ln N$. However, the increases are not parallel, as would be the case for a broken stick population structure. Thus, $E$ is not constant, the slope of $\ln E$ vs. $\ln N$ instead being $-0.23(\mathrm{r}=-0.99, p<0.005)$. For a logarithmic series distribution, the slopes of $\ln E$ and $\ln S$ when plotted against $\ln N$ would be equal but opposite. This is not the case here.

Using the last observed value of accumulated $H(3.67)$ to determine a logarithmic series structure likewise yields inconclusive results. Regression of $\ln S$ vs. $\ln E$, which would for a logarithmic series have a slope of -1 and an intercept of $H$, actually has an intercept of 2.95 but a slope of $-1.83(r=0.99$, $p<0.005)$. The predicted diversity for a logarithmic series when $N=964$ and $S=94$ is $E(H)=4.35$, which exceeds the final observed $H$ by 0.68 . The final predicted $E(H)$ for a logarithmic normal model, conversely, is 3.67, which is the same as the observed final value of accumulated $H$. However, the value of $\ln E / \ln S$ is not constant, as would be the case for a logarithmic normal distribution.

\section{DISCUSSION}

\section{Comparison of phytal substrates}

Buzas (2004) noted that there is not yet a consensus as to how far measures can depart from the ideal before the logarithmic series model is rejected for a particular population. Here, a population is accepted as having a logarithmic series distribution of species abundances if it shows three characteristics:

1. changes in the accumulative values of $H$ are not significantly correlated with the rise in accumulated $\ln N$ at a $95 \%$ confidence level, but are instead shown by linear regression to fluctuate around an almost stationary value;

2. regression of $\ln S$ against $\ln E$ gives a constant approximating to the final value of accumulated $H$ and a slope of approximately -1 ; and

3. the slopes of $\ln S$ and $\ln E$ vs. $\ln N$ are of opposite sign and approximately equal.

Because $H=\ln S+\ln E$, it follows that a population satisfying any one of the above conditions automatically satisfies the other two. Nevertheless, for completeness all three were examined. Application of these criteria to the foraminiferal populations on the six substrates sampled indicates that five ( $P$. capitatus capitulae in both LHB and MB, H. opuntia in MB and both $T$. testinudum leaves and rhizomes in LHB) supported foraminiferal populations with a logarithmic series population structure. The foraminiferal assemblage on $S$. filiforme did not show a good fit, the value of cumulative $H$ failing to attain an asymptote. This may be because this population was represented by too few samples and specimens.

General one-way Analysis of Variance (ANOVA) and Bonferroni's comparison of means were applied to the time-series of accumulated values of $H$ to investigate differences in diversity between foraminiferal communities in the two bays and on different plants. Mean accumulated $H$ on MB $H$. opuntia did not differ significantly from that on MB $S$. filiforme rhizomes, but the mean $H$ on both exceeded that on MB P. capitatus. Wilson \& Ramsook (2007) found a similar pattern for epiphytal foraminiferal assemblages in this bay when comparing the means of monthly values of $H$, rather than the mean of cumulative values of $H$. In contrast, findings in LHB differed from those reported by Wilson \& Ramsook (2007), who found that the mean monthly values of $H$ were indistinguishable for all substrates. In this bay the mean diversity on T. testinudum rhizomes, measured using the mean of the accumulated values of $H$, exceeded that on both $P$. capitatus capitulae and $T$. testinudum leaves. However, the mean values of accumulated $H$ on $P$. capitatus and $T$. testinudum leaves did not differ significantly. This suggests that Hayek \& Buzas' (1997) SHECSI might indicate differences in diversity with a precision not found by simple comparison of mean monthly values of $H$. The mean $H$ on $P$. capitatus in MB exceeded that on the same plant in LHB.

That seagrass rhizomes and short shoots, and $P$. capitatus capitulae, were sampled from both bays allows comparison of population structures on the same or similar plants at the two sites. However, because the foraminiferal community on $S$. filiforme did not readily fit any of the four population models, comparison here is restricted to foraminiferal populations on $P$. capitatus. Linear regression of accumulated $H$ against $\ln N$ reflects how these two populations differ in diversity; in LHB, $P$. capitatus $H$ is almost constant at $c$. 1.8 , whereas in $\mathrm{MB}$ it is almost constant at $c$. 2.65. It is generally accepted that species richness $S$ increases with the number of specimens $N$ (Buzas et al., 1977; Magurran, 1988, 2003; Hayek \& Buzas, 1997). Regression of $\ln S$ against $\ln N$ indicates that on $P$. capitatus the rate of increase in species richness differed little (MB, slope of $\ln S$ vs. $\ln N=0.393, r=0.958$; LHB, slope $=0.354, r=0.992)$, despite differences in overall diversity between the two bays. The rate of decline of $\ln E$ against $\ln N$ likewise differed little, despite the higher overall values of $E$ in $\mathrm{MB}$; on $\mathrm{MB} P$. capitatus the slope of $\ln E$ vs. $\ln N$ was $-0.373(r=0.972)$, whereas in LHB it was $0.312(r=0.941)$.

Comparison may also be made between communities on different substrates in the same bay. In LHB, the rate of increase of $\ln S$ against $\ln N$ on $P$. capitatus (slope $=0.354$ ) differed little from that on $T$. testinudum leaves (slope $=0.363$ ), but more markedly from that on $T$. testinudum rhizomes (slope $=0.439$; value above constant). These data might reflect the nature of the community; Wilson \& Ramsook (2007) concluded that, whereas short-lived substrates such as $P$. capitatus support lower diversity, permanently pioneering communities, longer-lived substrates such as seagrass rhizomes support climax communities of greater diversity. The rate of decrease of $\ln E$ against $\ln N$ on $P$. capitatus (slope $=-0.312$ ) was little different from that on T. testinudum leaves (slope $=-0.333$ ) or rhizomes (slope $=$ -0.322 ; value above asymptote). Thus, around Nevis, the rate 


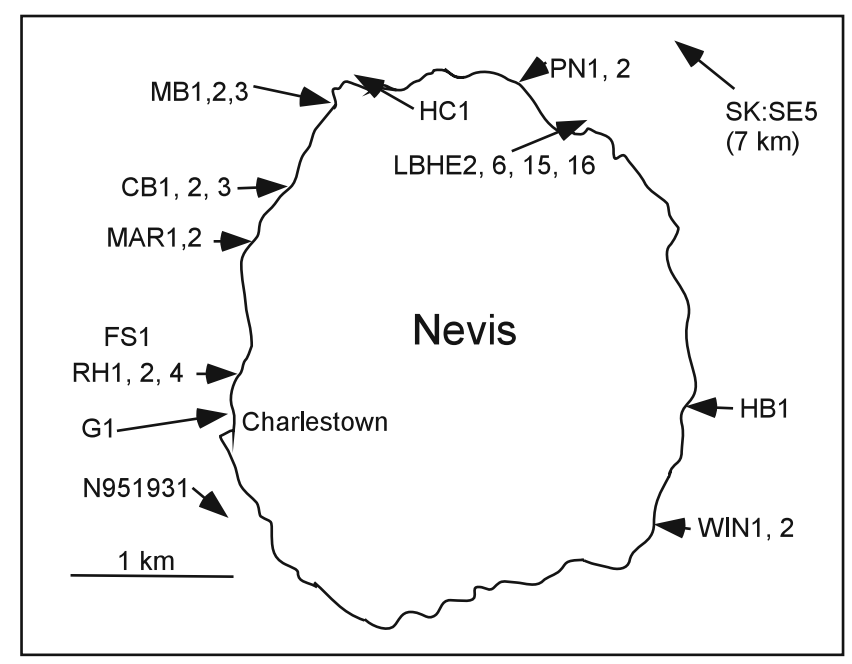

Fig. 5. Location of sediment samples around Nevis. Sample numbers from Wilson (2006b).

of increase of $\ln S$ is generally $c .0 .3$ to 0.4 , and the rate of decrease of $\ln E$ is $c$. -0.3 to -0.4 . However, these values are not universal constants. Buzas (2004) examined the population structure of the foraminiferal taxocene in two Miocene age beds in Maryland. While in one bed the slopes of $\ln S$ vs. $\ln N$ and $\ln E$ vs. $\ln N$ were 0.3 and 0.29 respectively, those in the other were 0.15 and -0.20 .

\section{Population structure of the sediment thanatacoenosis}

Wilson (2006a) documented the foraminiferal thanatacoenosis in twenty-five samples from shallow-water $(<3 \mathrm{~m})$ sediments around Nevis (Fig. 5, Table 3). Because nearshore seagrass meadows around Nevis are limited virtually to LHB and MB, bare sands were sampled at all locations, confounding the possible occurrence of live foraminifera in sediment bound by seagrasses (cf. Buzas et al., 1977) by collecting samples from bare patches, such as anchor scars, within the seagrass meadows. As interest was focused on how the total sediment assemblage compares with the epiphytal biocoenosis, the samples were not stained with rose Bengal.

The thanatacoenosis comprised 134 species of foraminifera, of which 20 each formed $>1 \%$ of the total recovery. The principal differences between the epiphytal and sediment assemblages in shallow water in LHB were (a) the common occurrence of attached planorbulinids on seagrass leaves and their rarity in sediments, and (b) the greater percentage abundances of Archaias angulatus, Amphistegina gibbosa and A. carinata in the sediment than on plants. Because $A$. gibbosa and $A$. carinata are primarily reefal species (Todd \& Low, 1976; Gischler et al., 2003) and $A$. angulatus occupies the deeper backreef (Martin, 1986), the differences between the LHB biocoenoses and the shallowwater thanatacoenosis may be credited to shoreward transport of sediment during hurricanes (cf. Li et al., 1997). In MB the epiphytal biocoenosis was dominated by Triloculina rotunda, with lesser Tretomphalus bulloides, while the sediment thanatacoenosis was dominated by Discorbis rosea. Given that epiphytal foraminiferal populations in MB showed nonstationary dynamics, the differences in MB may be ascribed to the impact of the organic flux on the composition of the epiphytal biocoenosis, coupled with the influence of sediment transport by storms.

Cluster analysis by Wilson (2006a) revealed six clusters, but most comprised few samples, fifteen of the twenty-five samples from diverse locations around the island grouping as a generalized cluster. This was interrupted at various places (especially along the north coast and in Cades Bay, a small embayment south of MB) by other, smaller clusters. A greater percentage of A. angulatus is glauconitized on the western, leeward coast, including in MB, than along the windward. Wilson (2006b) ascribed this to a lower rate of sediment reworking by waves along the lower energy, leeward coast. Nevertheless, Wilson (2006a) found samples from the windward and leeward coasts to cluster together.

Buzas \& Hayek (1998) suggested that a second form of SHE Analysis, SHEBI or SHE Analysis for Biofacies Identification, can be used to differentiate biofacies. Accumulated values of $\ln E$ along transects are sensitive indicators of biofacies boundaries, any increase in $\ln E$ indicating a change in biofacies. It might seem at first sight that this technique could be applied to the 25 Nevisian samples, which form a transect around the island. However, because SHEBI can be used only to recognize biofacies boundaries, and not recurrent species assemblages, it was not applied here. Instead, SHECSI was used to examine the foraminiferal population structure in the largest biofacies revealed from cluster analysis.

Samples were accumulated in order of increasing distance from the cluster centroid. Regression of accumulated $H$ against $\ln N$ (Fig. 6) indicated a logarithmic series structure $(H=2.27+0.066 \ln N, r=0.417, p=0.122)$, while regression lines for $\ln S$ and $\ln E$ against $\ln N$ revealed almost equal and opposite slopes, with a good fit between the data and the calculated regression lines $(\ln S=1.729+0.344 \ln N, \quad r=0.942, \quad p<0.005$; $\ln E=0.542-0.278 \ln N, r=0.911, p<0.005)$. The fifteen samples yielded 5503 foraminifera in 109 species, for which $\alpha=19.27$. This equated to an expected final $H$ of $E(H)=\ln 19.27+$ $0.58=3.54$. When $\ln S$ was regressed against $\ln E$, it gave an intercept (2.65), close to both $\hat{H}(2.78)$ and the final value of accumulated $H(2.93)$, and had a slope $(-1.081)$ very close to -1.0 . Thus, the foraminiferal thanatacoenosis in the cluster shows a logarithmic series distribution.

Two factors must be borne in mind when comparing the total sediment thanatacoenosis with the epiphytal biocoenoses.

1. The thanatacoenosis includes allochthonous species. Of the specimens recovered from the cluster, $40 \%$ comprised Amphistegina gibbosa, Archaias angulatus and Asterigerina carinata washed in from further offshore.

2. Whereas the sediment thanatacoenosis yielded only $0.3 \%$ planorbulinids, which live permanently attached to seagrass leaves, Wilson \& Ramsook (2007) documented that the Thalassia leaf biocoenosis in LHB included 55\% planorbulinids (Planogypsina squammiformis, Planorbulina acervalis, $P$. mediterranensis and $P$. retinaculata). The paucity of planorbulinids in the sediment might be due to breakage of the fragile tests after death. Alternatively, planorbulinids might be transported out of the bay attached to the leaves on which they live; Stapel et al. (1996) found that seagrass blades are shed after c. 30 days, and that c. $25 \%$ of discarded above-ground seagrass biomass is transported seawards. 
Sample number

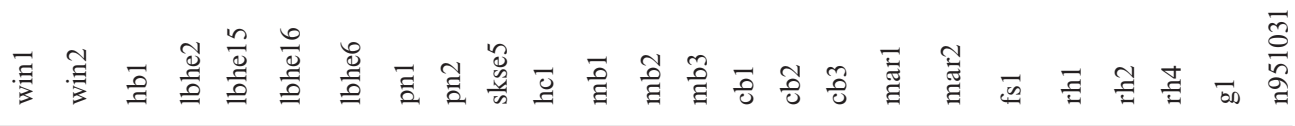

Acervulina inhaerens Agglutinella cf. robusta

Agglutinella soriformis?

Ammomassilina alveoliniformis

Ammonia sobrina

Ammonia tepida

Amphistegina gibbosa

Archaias angulatus

Articulina atlantica

Articulina mayori

Articulina mucronata

Articulina sagra

Asterigerina carinata

Bolivina striatula

Borelis pulchra

Broeckina orbitolitoides

Cancris sagra

Cibicides cf. robertsoniana

Cibicides lobatulus

Cibicides pseudoungerianus

Cibicides sp. A

Cibicides sp. B

Cibicides sp. C

Cibicides sp. cf. mayori

Clavulina angularis

Cornuspira involvens

Coryphostoma? limbata var. costulata

Cymbaloporetta atlantica

Cymbaloporetta bradyi

Cymbaloporetta squammosa

Discorbis granulosa

Discorbis mira

Discorbis rosea

Elphidium advenum

Elphidium cf. poeyanum

Elphidium discoidale

Elphidium mexicana

Elphidium poeyanum

Elphidium sagrum

Eponides antillarum

Fissurina goreaui

Fursenkoina pontoni

Glabratella brasiliensis

Globigerinoides ruber

Hauerina bradyi

Hauerina ornatissima

Hauerina pacifica

Heterostegina antillarum

Massilina gualtieriana

Massilina inaequalis

Miliolid gen. and sp.indet.

Miliolinella circularis

Miliolinella labiosa

Miliolinella suborbicularis

Miliolinella viguerasi

Monalysidium politum

Neoconorbina terquemi

Nodobaculariella mexicana

Nodopthalmidium antillarum

Nodosaria catesbyi

Nonion sp.

Nonionella cuevasensis

$\begin{array}{llllllllllllllllllllllllll}0 & 0 & 0 & 0 & 0 & 0 & 0 & 0 & 0 & 0 & 0 & 0 & 0 & 0 & 0 & 12 & 2 & 0 & 0 & 0 & 0 & 0 & 0 & 0 & 0\end{array}$

$\begin{array}{lllllllllllllllllllllllllllllllllll}0 & 0 & 0 & 0 & 0 & 0 & 0 & 0 & 0 & 0 & 1 & 0 & 0 & 0 & 0 & 4 & 6 & 0 & 0 & 1 & 3 & 0 & 0 & 0 & 0\end{array}$

$\begin{array}{llllllllllllllllllllllllllllllllll}0 & 0 & 0 & 0 & 0 & 0 & 2 & 0 & 0 & 0 & 0 & 0 & 0 & 0 & 0 & 0 & 0 & 0 & 0 & 0 & 0 & 0 & 0 & 0 & 0\end{array}$

$\begin{array}{lllllllllllllllllllllllllllllllll}0 & 0 & 0 & 0 & 0 & 0 & 0 & 0 & 0 & 0 & 0 & 0 & 0 & 0 & 0 & 0 & 0 & 0 & 0 & 0 & 0 & 3 & 0 & 0 & 0\end{array}$

$\begin{array}{rllllllllllllllllllllllllllll}0 & 0 & 0 & 0 & 0 & 0 & 0 & 0 & 0 & 0 & 0 & 18 & 16 & 20 & 0 & 9 & 14 & 3 & 4 & 1 & 8 & 7 & 7 & 10 & 0\end{array}$

$\begin{array}{llllllllllllllllllllllllllllll}0 & 0 & 0 & 0 & 0 & 0 & 1 & 0 & 0 & 1 & 0 & 2 & 3 & 1 & 8 & 0 & 1 & 0 & 0 & 0 & 1 & 0 & 0 & 1 & 1\end{array}$

$\begin{array}{lllllllllllllllllllllllll}33 & 46 & 75 & 69 & 8 & 10 & 14 & 32 & 23 & 20 & 51 & 43 & 15 & 12 & 8 & 6 & 5 & 28 & 32 & 53 & 18 & 39 & 25 & 40 & 12\end{array}$

$\begin{array}{llllllllllllllllllllllllllllll}16 & 24 & 43 & 18 & 5 & 5 & 19 & 74 & 73 & 3 & 68 & 106 & 29 & 34 & 10 & 18 & 5 & 59 & 68 & 72 & 36 & 15 & 37 & 17 & 12\end{array}$

$\begin{array}{lllllllllllllllllllllllllllll}1 & 0 & 0 & 1 & 0 & 0 & 0 & 0 & 0 & 3 & 0 & 0 & 0 & 0 & 0 & 0 & 0 & 0 & 0 & 0 & 0 & 0 & 0 & 0 & 0\end{array}$

$\begin{array}{lllllllllllllllllllllllllllllllll}0 & 0 & 0 & 0 & 0 & 0 & 0 & 0 & 0 & 0 & 0 & 0 & 0 & 2 & 0 & 2 & 0 & 0 & 0 & 0 & 0 & 0 & 0 & 0 & 0\end{array}$

$\begin{array}{llllllllllllllllllllllllllllll}0 & 0 & 0 & 0 & 0 & 0 & 0 & 1 & 0 & 6 & 0 & 0 & 0 & 0 & 22 & 27 & 0 & 0 & 2 & 0 & 3 & 1 & 0 & 0 & 7\end{array}$

$\begin{array}{llllllllllllllllllllllllllllll}0 & 0 & 0 & 3 & 0 & 1 & 4 & 0 & 0 & 0 & 0 & 0 & 2 & 6 & 0 & 0 & 12 & 0 & 0 & 0 & 0 & 0 & 4 & 1 & 1\end{array}$

$\begin{array}{rrrrrrrrrrrrrrrrrrrrrrrrr}52 & 40 & 7 & 20 & 1 & 3 & 11 & 3 & 26 & 48 & 2 & 10 & 10 & 20 & 21 & 18 & 21 & 62 & 34 & 16 & 43 & 46 & 37 & 44 & 22\end{array}$

$\begin{array}{lllllllllllllllllllllllllllllll}0 & 0 & 0 & 6 & 0 & 0 & 2 & 0 & 0 & 0 & 0 & 0 & 1 & 0 & 8 & 2 & 0 & 0 & 0 & 0 & 0 & 0 & 0 & 1 & 0\end{array}$

$\begin{array}{lllllllllllllllllllllllllllllll}4 & 13 & 10 & 6 & 3 & 3 & 5 & 4 & 0 & 1 & 0 & 3 & 2 & 3 & 0 & 0 & 0 & 2 & 0 & 2 & 0 & 4 & 1 & 1 & 0\end{array}$

$\begin{array}{lllllllllllllllllllllllll}2 & 0 & 0 & 0 & 0 & 0 & 0 & 0 & 1 & 7 & 0 & 2 & 1 & 5 & 7 & 4 & 3 & 4 & 2 & 3 & 5 & 8 & 4 & 2 & 5\end{array}$

$\begin{array}{lllllllllllllllllllllllllllllllllllllllll}0 & 0 & 0 & 0 & 0 & 0 & 0 & 0 & 0 & 0 & 0 & 0 & 0 & 0 & 2 & 4 & 0 & 0 & 0 & 0 & 0 & 0 & 0 & 0 & 0\end{array}$

$\begin{array}{llllllllllllllllllllllllllllllll}0 & 0 & 0 & 2 & 0 & 0 & 0 & 0 & 0 & 0 & 0 & 0 & 0 & 0 & 0 & 0 & 0 & 0 & 0 & 0 & 0 & 0 & 0 & 0 & 0\end{array}$

$\begin{array}{llllllllllllllllllllllllllllllll}0 & 0 & 0 & 0 & 0 & 0 & 0 & 0 & 0 & 10 & 0 & 0 & 0 & 0 & 0 & 0 & 0 & 0 & 0 & 0 & 0 & 0 & 0 & 0 & 0\end{array}$

$\begin{array}{lllllllllllllllllllllllllllll}3 & 3 & 0 & 10 & 0 & 0 & 4 & 0 & 0 & 3 & 0 & 0 & 3 & 0 & 1 & 0 & 0 & 0 & 0 & 0 & 0 & 1 & 5 & 8 & 4\end{array}$

$\begin{array}{lllllllllllllllllllllllllllllllllll}0 & 0 & 0 & 0 & 0 & 0 & 0 & 0 & 0 & 0 & 0 & 0 & 0 & 0 & 0 & 0 & 0 & 0 & 0 & 0 & 0 & 0 & 0 & 1 & 0\end{array}$

$\begin{array}{llllllllllllllllllllllllll}0 & 0 & 0 & 0 & 0 & 0 & 0 & 0 & 0 & 0 & 0 & 0 & 0 & 0 & 3 & 1 & 0 & 0 & 0 & 0 & 0 & 0 & 0 & 0 & 0\end{array}$

$\begin{array}{llllllllllllllllllllllllllllllllllllll}0 & 0 & 0 & 3 & 0 & 0 & 0 & 0 & 0 & 0 & 0 & 0 & 0 & 0 & 0 & 0 & 0 & 0 & 0 & 0 & 0 & 0 & 0 & 0 & 0\end{array}$

$\begin{array}{lllllllllllllllllllllllllllllllllll}0 & 0 & 0 & 0 & 0 & 0 & 4 & 0 & 0 & 0 & 0 & 0 & 0 & 0 & 0 & 0 & 0 & 0 & 0 & 0 & 0 & 0 & 0 & 0 & 2\end{array}$

$\begin{array}{lllllllllllllllllllllllllllllllllll}0 & 0 & 0 & 0 & 0 & 0 & 0 & 1 & 0 & 0 & 0 & 0 & 1 & 0 & 0 & 2 & 0 & 0 & 0 & 2 & 0 & 1 & 0 & 0 & 1\end{array}$

$\begin{array}{llllllllllllllllllllllllllllllll}0 & 0 & 0 & 0 & 1 & 0 & 1 & 0 & 0 & 0 & 0 & 0 & 1 & 0 & 2 & 2 & 0 & 0 & 0 & 0 & 0 & 0 & 0 & 0 & 0\end{array}$

$\begin{array}{llllllllllllllllllllllllllllllllllll}0 & 0 & 0 & 1 & 0 & 0 & 0 & 0 & 0 & 0 & 0 & 1 & 0 & 0 & 0 & 0 & 0 & 0 & 0 & 0 & 0 & 0 & 0 & 0 & 0\end{array}$

$\begin{array}{lllllllllllllllllllllllllllllllllllll}0 & 0 & 0 & 0 & 0 & 0 & 0 & 0 & 0 & 4 & 0 & 0 & 0 & 0 & 0 & 1 & 1 & 0 & 0 & 0 & 0 & 1 & 1 & 0 & 0\end{array}$

$\begin{array}{lllllllllllllllllllllllllllllllllllll}0 & 0 & 0 & 0 & 0 & 0 & 0 & 0 & 0 & 0 & 0 & 1 & 0 & 0 & 0 & 0 & 0 & 0 & 0 & 0 & 0 & 0 & 0 & 0 & 0\end{array}$

$\begin{array}{llllllllllllllllllllllllllllllllll}1 & 0 & 0 & 6 & 0 & 0 & 3 & 4 & 25 & 6 & 0 & 1 & 2 & 3 & 2 & 4 & 0 & 1 & 1 & 0 & 4 & 3 & 2 & 1 & 0\end{array}$

$\begin{array}{lllllllllllllllllllllllllllllll}0 & 4 & 0 & 2 & 1 & 2 & 0 & 10 & 3 & 3 & 3 & 10 & 5 & 12 & 0 & 0 & 0 & 0 & 0 & 0 & 5 & 0 & 2 & 2 & 0\end{array}$

$\begin{array}{rrrrrrrrrrrrrrrrrrrrrrrrrrrrrrr}15 & 5 & 6 & 19 & 15 & 9 & 14 & 1 & 3 & 8 & 1 & 1 & 11 & 20 & 12 & 11 & 8 & 3 & 0 & 0 & 9 & 5 & 1 & 14 & 9\end{array}$

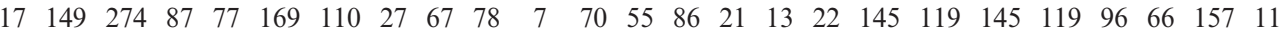

$\begin{array}{lllllllllllllllllllllllllllllllll}0 & 0 & 0 & 0 & 0 & 0 & 0 & 0 & 0 & 2 & 0 & 0 & 0 & 0 & 0 & 1 & 3 & 0 & 1 & 0 & 1 & 2 & 1 & 0 & 4\end{array}$

$\begin{array}{llllllllllllllllllllllllllllllll}0 & 0 & 0 & 0 & 0 & 0 & 0 & 0 & 0 & 0 & 0 & 0 & 0 & 0 & 0 & 4 & 3 & 0 & 0 & 0 & 0 & 1 & 0 & 0 & 0\end{array}$

$\begin{array}{rrrrrrrrrrrrrrrrrrrrrrrrrrrrrrrrr}0 & 1 & 0 & 0 & 0 & 0 & 1 & 0 & 0 & 5 & 0 & 2 & 7 & 11 & 12 & 9 & 8 & 20 & 14 & 3 & 12 & 6 & 15 & 9 & 12\end{array}$

$\begin{array}{llllllllllllllllllllllllllllllll}0 & 1 & 0 & 0 & 0 & 0 & 0 & 0 & 0 & 2 & 0 & 0 & 0 & 0 & 2 & 4 & 0 & 0 & 0 & 0 & 3 & 3 & 1 & 0 & 0\end{array}$

$\begin{array}{llllllllllllllllllllllllllllllll}0 & 0 & 0 & 0 & 0 & 0 & 0 & 0 & 0 & 0 & 0 & 0 & 2 & 2 & 10 & 10 & 17 & 0 & 0 & 0 & 3 & 0 & 4 & 1 & 3\end{array}$

$\begin{array}{llllllllllllllllllllllllllllll}0 & 1 & 0 & 1 & 0 & 1 & 0 & 0 & 0 & 0 & 0 & 4 & 0 & 10 & 5 & 4 & 1 & 9 & 7 & 5 & 5 & 9 & 7 & 10 & 0\end{array}$

$\begin{array}{lllllllllllllllllllllllllllllll}0 & 0 & 0 & 0 & 0 & 0 & 0 & 1 & 2 & 1 & 0 & 1 & 3 & 1 & 0 & 4 & 1 & 0 & 5 & 1 & 3 & 2 & 1 & 1 & 0\end{array}$

$\begin{array}{llllllllllllllllllllllllllllll}0 & 0 & 0 & 0 & 0 & 0 & 1 & 0 & 0 & 0 & 0 & 0 & 0 & 0 & 0 & 0 & 0 & 0 & 0 & 0 & 0 & 0 & 0 & 0 & 0\end{array}$

$\begin{array}{lllllllllllllllllllllllllllllllllllllllll}0 & 0 & 0 & 0 & 0 & 0 & 1 & 0 & 0 & 0 & 0 & 1 & 1 & 1 & 5 & 3 & 5 & 0 & 0 & 0 & 1 & 0 & 0 & 0 & 0\end{array}$

$\begin{array}{llllllllllllllllllllllllllllllll}0 & 0 & 0 & 0 & 0 & 0 & 0 & 0 & 0 & 1 & 0 & 0 & 0 & 0 & 0 & 0 & 0 & 0 & 0 & 0 & 0 & 0 & 0 & 0 & 2\end{array}$

$\begin{array}{llllllllllllllllllllllllllllll}1 & 0 & 0 & 8 & 0 & 0 & 0 & 0 & 0 & 0 & 0 & 0 & 0 & 0 & 0 & 3 & 0 & 0 & 0 & 0 & 5 & 0 & 0 & 0 & 7\end{array}$

$\begin{array}{llllllllllllllllllllllllllllll}4 & 0 & 1 & 0 & 0 & 1 & 4 & 0 & 0 & 2 & 0 & 1 & 6 & 4 & 8 & 1 & 7 & 0 & 0 & 0 & 0 & 3 & 1 & 0 & 3\end{array}$

$\begin{array}{lllllllllllllllllllllllllllllllllll}6 & 1 & 0 & 2 & 2 & 0 & 5 & 0 & 0 & 2 & 0 & 1 & 1 & 2 & 0 & 0 & 0 & 0 & 0 & 0 & 0 & 0 & 0 & 1 & 4\end{array}$

$\begin{array}{llllllllllllllllllllllllll}0 & 0 & 0 & 0 & 0 & 0 & 0 & 0 & 0 & 1 & 0 & 0 & 0 & 0 & 0 & 0 & 0 & 0 & 0 & 0 & 0 & 0 & 0 & 0 & 0\end{array}$

$\begin{array}{lllllllllllllllllllllllllllllllllllllllll}9 & 7 & 2 & 0 & 1 & 1 & 2 & 0 & 1 & 5 & 2 & 1 & 1 & 0 & 1 & 0 & 0 & 3 & 1 & 0 & 3 & 1 & 2 & 1 & 2\end{array}$

$\begin{array}{lllllllllllllllllllllllllllllllll}4 & 0 & 0 & 6 & 0 & 0 & 2 & 1 & 0 & 0 & 0 & 0 & 0 & 0 & 0 & 1 & 0 & 0 & 0 & 0 & 7 & 2 & 3 & 0 & 0\end{array}$

$\begin{array}{llllllllllllllllllllllllllllllll}0 & 0 & 0 & 0 & 0 & 0 & 0 & 0 & 0 & 0 & 0 & 0 & 0 & 1 & 0 & 28 & 5 & 0 & 0 & 0 & 0 & 5 & 0 & 6 & 0\end{array}$

$\begin{array}{llllllllllllllllllllllllllllll}0 & 0 & 0 & 0 & 0 & 0 & 0 & 0 & 0 & 1 & 0 & 0 & 0 & 0 & 0 & 0 & 0 & 0 & 0 & 0 & 0 & 0 & 0 & 0 & 0\end{array}$

$\begin{array}{lllllllllllllllllllllllllllllllll}1 & 0 & 1 & 1 & 4 & 0 & 10 & 0 & 0 & 0 & 0 & 1 & 0 & 0 & 15 & 11 & 8 & 0 & 0 & 0 & 1 & 3 & 0 & 0 & 0\end{array}$

$\begin{array}{lllllllllllllllllllllllllllllll}0 & 0 & 0 & 0 & 0 & 0 & 0 & 0 & 0 & 1 & 0 & 0 & 0 & 0 & 0 & 0 & 0 & 0 & 0 & 0 & 0 & 0 & 0 & 0 & 0\end{array}$

$\begin{array}{llllllllllllllllllllllllllllllll}11 & 0 & 0 & 7 & 0 & 0 & 11 & 0 & 0 & 15 & 0 & 2 & 1 & 4 & 8 & 7 & 3 & 0 & 0 & 0 & 2 & 0 & 4 & 0 & 5\end{array}$

$\begin{array}{lllllllllllllllllllllllllllllllll}14 & 0 & 0 & 2 & 1 & 0 & 16 & 0 & 0 & 18 & 0 & 1 & 0 & 0 & 0 & 0 & 0 & 0 & 0 & 0 & 0 & 1 & 3 & 2 & 0\end{array}$

$\begin{array}{llllllllllllllllllllllllllllllll}0 & 0 & 0 & 0 & 0 & 0 & 0 & 0 & 0 & 0 & 0 & 0 & 0 & 2 & 0 & 0 & 1 & 0 & 0 & 0 & 0 & 0 & 0 & 0 & 0\end{array}$

$\begin{array}{lllllllllllllllllllllllllllllllllll}0 & 0 & 0 & 3 & 0 & 0 & 0 & 0 & 0 & 0 & 0 & 0 & 0 & 0 & 5 & 5 & 0 & 0 & 0 & 0 & 0 & 0 & 0 & 0 & 0\end{array}$

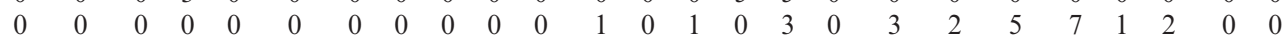

$\begin{array}{lllllllllllllllllllllllllllllllllll}0 & 0 & 0 & 0 & 0 & 0 & 0 & 0 & 0 & 0 & 0 & 0 & 0 & 0 & 2 & 0 & 0 & 0 & 0 & 0 & 0 & 0 & 0 & 0 & 0\end{array}$

$\begin{array}{llllllllllllllllllllllllllllllllll}0 & 0 & 0 & 0 & 0 & 0 & 0 & 0 & 0 & 0 & 0 & 0 & 0 & 0 & 0 & 0 & 0 & 0 & 0 & 0 & 0 & 0 & 0 & 0 & 1\end{array}$

$\begin{array}{rllllllllllllllllllllllllllll}0 & 0 & 0 & 0 & 0 & 0 & 0 & 0 & 0 & 0 & 0 & 0 & 0 & 0 & 0 & 0 & 0 & 0 & 0 & 0 & 0 & 0 & 1 & 0 & 0 \\ 1 & 0 & 0 & 3 & 0 & 0 & 3 & 0 & 2 & 13 & 0 & 2 & 1 & 2 & 2 & 0 & 0 & 2 & 3 & 0 & 0 & 1 & 0 & 0 & 0\end{array}$ 
Sample number

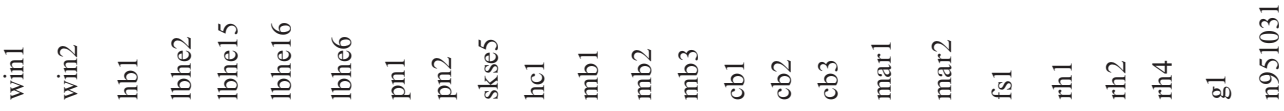

Nonionella grateloupi

Nonionella? sp.

Peneroplis bradyi

Peneroplis carinatus

Peneroplis pertusus

Peneroplis proteus

Planogypsina squammiformis

Planorbulina mediterranensis

Planorbulina retinaculata

Pyrgo denticulata

Pyrgo jugosa

Pyrgo subsphaerica

Quinqueloculina auberiana

Quinqueloculina bosciana

Quinqueloculina carinastriata

Quinqueloculina carinata

Quinqueloculina cf. cruziana

Quinqueloculina cf. quadrilateralis

Quinqueloculina crassicarinata

Quinqueloculina exsculpta

Quinqueloculina lamarckiana

Quinqueloculina longirostra

Quinqueloculina parkeri var. occidentalis

Quinqueloculina philippinensis

Quinqueloculina poeyana

Ouinqueloculina polygona

Quinqueloculina seminula

Quinqueloculina sp. C

Quinqueloculina sp. cf. Triloculina eburnea

Quinqueloculina transversestriata

Quinqueloculina tricarinata

Quinqueloculina venezuelaensis

Rectobolivina raphana

Reophax bacillaris

Reussella mortensi

Rosalina bahamaensis

Rosalina bradyi

Rosalina floridensis

Rosalina orientalis

Rosalina subaraucana

Sagrina pulchella

Sigmavirgulina tortuosa

Sigmoilopsis arenata

Siphonaperta bidentata

Siphonina pulchra

Siphoninoides echinata

Sorites orbiculus

Spirillina vivipara

Spirolina arietina

Spiroloculina angulata

Spiroloculina antillarum

Spiroloculina eximia

Spiroloculina sp. A

Textularia agglutinans

Textularia candeiana

Textularia cf. conica

Tretomphalus bulloides

Trichohyalus aguayoi

Triloculina bassensis

Triloculina cf. bertheliniana

$\begin{array}{rrrrrr}0 & 0 & 0 & 0 & 0 & 0 \\ 0 & 0 & 0 & 1 & 0 & 0 \\ 1 & 0 & 0 & 4 & 0 & 0 \\ 6 & 0 & 10 & 0 & 0 & 1 \\ 28 & 10 & 1 & 2 & 0 & 1 \\ 15 & 29 & 0 & 16 & 3 & 4 \\ 4 & 0 & 0 & 3 & 3 & 0 \\ 8 & 0 & 0 & 0 & 2 & 1 \\ 5 & 0 & 0 & 0 & 0 & 0 \\ 0 & 0 & 0 & 0 & 0 & 0 \\ 0 & 0 & 0 & 0 & 0 & 0 \\ 0 & 0 & 0 & 1 & 0 & 0 \\ 0 & 0 & 0 & 0 & 0 & 0 \\ 1 & 0 & 0 & 4 & 2 & 1 \\ 0 & 0 & 0 & 0 & 0 & 0 \\ 0 & 0 & 0 & 0 & 0 & 0 \\ 4 & 5 & 0 & 5 & 0 & 0 \\ 0 & 0 & 0 & 0 & 0 & 0 \\ 0 & 0 & 0 & 0 & 0 & 0 \\ 0 & 0 & 0 & 0 & 0 & 0 \\ 0 & 0 & 0 & 0 & 0 & 0 \\ 0 & 0 & 0 & 0 & 0 & 0 \\ 0 & 0 & 0 & 0 & 1 & 0 \\ & & & & & \end{array}$

2

\section{$\begin{array}{llll}0 & 0 & 0 & 0\end{array}$}

$\begin{array}{rrrrrrrrrrrrrrrrrrr}1 & 0 & 0 & 7 & 0 & 0 & 0 & 0 & 2 & 3 & 3 & 0 & 0 & 0 & 0 & 0 & 0 & 0 & 1\end{array}$

$\begin{array}{lllllllllllllllllll}4 & 4 & 14 & 0 & 0 & 14 & 0 & 11 & 5 & 4 & 0 & 38 & 44 & 23 & 28 & 12 & 24 & 17 & 0\end{array}$

$\begin{array}{lllllllllllllllllll}10 & 0 & 7 & 13 & 0 & 1 & 4 & 1 & 5 & 1 & 4 & 0 & 1 & 0 & 3 & 1 & 2 & 6 & 0\end{array}$

$\begin{array}{lllllllllllllllllll}10 & 6 & 27 & 18 & 1 & 5 & 20 & 13 & 5 & 7 & 11 & 6 & 11 & 1 & 12 & 17 & 21 & 12 & 8\end{array}$

$\begin{array}{lllllllllllllllllll}0 & 0 & 0 & 1 & 0 & 6 & 1 & 3 & 1 & 9 & 4 & 0 & 0 & 0 & 0 & 1 & 0 & 0 & 0\end{array}$

$\begin{array}{rllllllllllllllllll}2 & 0 & 1 & 0 & 0 & 0 & 1 & 0 & 7 & 36 & 4 & 0 & 0 & 0 & 0 & 1 & 0 & 0 & 1\end{array}$

$\begin{array}{lllllllllllllllllll}2 & 0 & 0 & 0 & 0 & 0 & 0 & 0 & 2 & 0 & 0 & 0 & 0 & 0 & 0 & 0 & 0 & 0 & 0\end{array}$

$\begin{array}{lllllllllllllllllll}0 & 0 & 0 & 0 & 0 & 1 & 0 & 1 & 4 & 2 & 1 & 0 & 2 & 0 & 0 & 1 & 0 & 0 & 0\end{array}$

$\begin{array}{lllllllllllllllllll}0 & 0 & 0 & 0 & 0 & 0 & 0 & 0 & 0 & 3 & 0 & 0 & 0 & 1 & 0 & 0 & 0 & 0 & 2\end{array}$

$\begin{array}{lllllllllllllllllll}0 & 0 & 0 & 0 & 0 & 0 & 0 & 2 & 3 & 0 & 4 & 0 & 0 & 0 & 0 & 1 & 0 & 0 & 0\end{array}$

$\begin{array}{lllllllllllllllllll}0 & 0 & 0 & 0 & 0 & 11 & 2 & 11 & 0 & 0 & 8 & 50 & 23 & 0 & 11 & 9 & 0 & 0 & 0\end{array}$

$\begin{array}{lllllllllllllllllll}3 & 0 & 0 & 0 & 0 & 1 & 6 & 9 & 38 & 6 & 8 & 0 & 0 & 0 & 0 & 0 & 3 & 0 & 1\end{array}$

$\begin{array}{lllllllllllllllllll}0 & 0 & 0 & 0 & 0 & 0 & 0 & 0 & 4 & 0 & 0 & 0 & 0 & 0 & 0 & 0 & 0 & 0 & 0\end{array}$

$\begin{array}{lllllllllllllllllll}0 & 0 & 0 & 0 & 1 & 1 & 0 & 3 & 0 & 9 & 1 & 0 & 0 & 0 & 5 & 0 & 0 & 0 & 1\end{array}$

$\begin{array}{lllllllllllllllllll}16 & 1 & 6 & 0 & 0 & 11 & 11 & 5 & 0 & 11 & 6 & 0 & 3 & 0 & 0 & 0 & 1 & 3 & 0\end{array}$

$\begin{array}{lllllllllllllllllll}0 & 0 & 1 & 0 & 0 & 0 & 0 & 0 & 0 & 0 & 0 & 0 & 0 & 0 & 0 & 0 & 0 & 0 & 0\end{array}$

$\begin{array}{lllllllllllllllllll}0 & 0 & 0 & 0 & 0 & 0 & 0 & 0 & 0 & 0 & 0 & 0 & 0 & 0 & 0 & 0 & 0 & 0 & 4\end{array}$

$\begin{array}{lllllllllllllllllll}0 & 0 & 0 & 0 & 0 & 0 & 0 & 0 & 1 & 0 & 1 & 0 & 0 & 0 & 0 & 0 & 0 & 0 & 0\end{array}$

$\begin{array}{lllllllllllllllllll}0 & 0 & 0 & 6 & 1 & 4 & 4 & 29 & 32 & 13 & 8 & 7 & 9 & 29 & 9 & 9 & 0 & 26 & 17\end{array}$

$\begin{array}{lllllllllllllllllll}0 & 0 & 0 & 1 & 0 & 0 & 0 & 0 & 0 & 0 & 0 & 0 & 0 & 0 & 0 & 0 & 0 & 0 & 0\end{array}$

$\begin{array}{lllllllllllllllllllllllllll}0 & 0 & 2 & 0 & 1 & 0 & 0 & 0 & 1 & 0 & 0 & 0 & 0 & 0 & 0 & 0 & 1 & 0 & 1 & 0 & 0\end{array}$




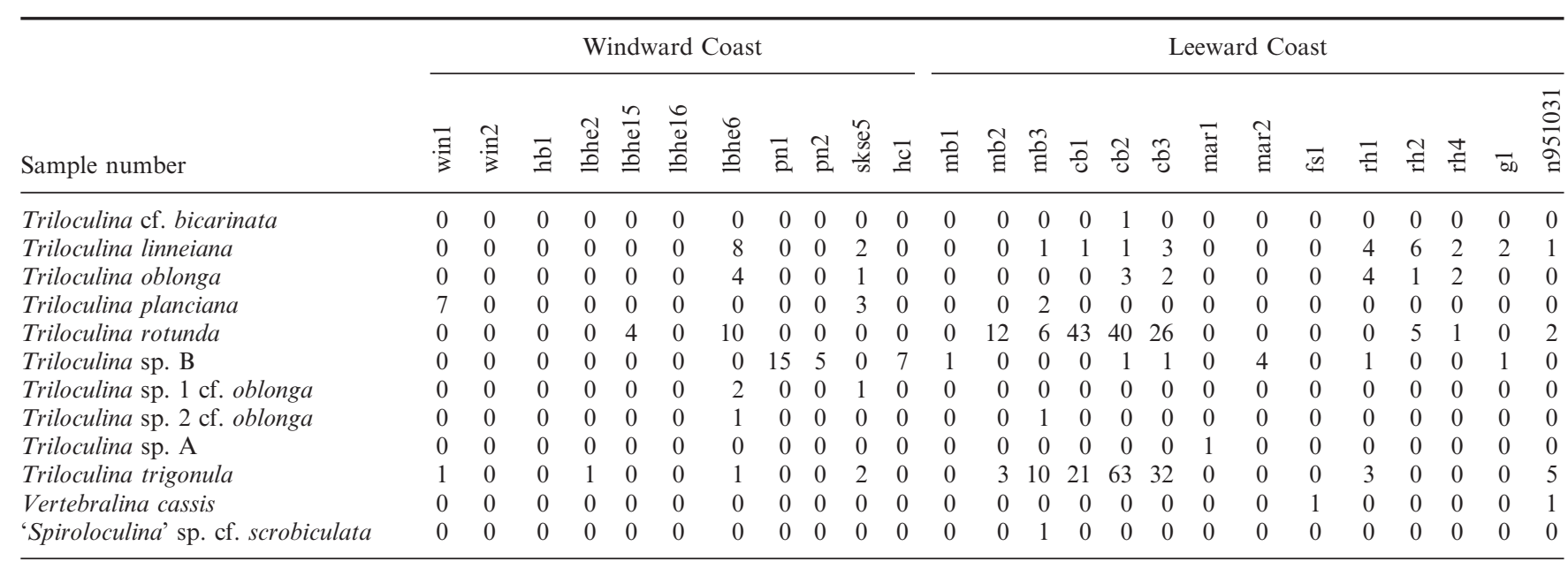

Samples are arranged in a series that progresses anticlockwise around the island. Sample numbers from Wilson (1998).

Table 3. Foraminifera in sediment samples around Nevis.

\section{CONCLUSIONS}

Epiphytal foraminiferal populations were monitored monthly on six phytal substrates in shallow water $(<1 \mathrm{~m})$ in two bays around the island of Nevis, in an environment where the sediment assemblage consists mainly of dead specimens washed from associated plants, or allochthonous specimens washed inshore during storms. SHE Community Structure Investigations (SHECSIs) revealed that, of six epiphytal foraminiferal time-series examined, five had logarithmic series distributions of species abundances. The sixth (Syringodium filiforme rhizomes) was apparently represented by too few foraminifera in too few samples to indicate a population structure definitively. The main indicator of a logarithmic series distribution is that cumulative $H$, when regressed against cumulative $\ln N$, is constant. None of the populations showed a perfect fit to this parameter, but, for five, $H$ fluctuated around a constant. In a perfect time-series, the slope of a regression of $\ln S$ against $\ln E$ is -1 . For all five time-series for which cumulative $H$ fluctuated around a constant, the slope of $\ln S$ vs. $\ln E$ was $-1 \pm 0.3$. In four time-series the slope was $-1 \pm 0.2$ and, for three time-series

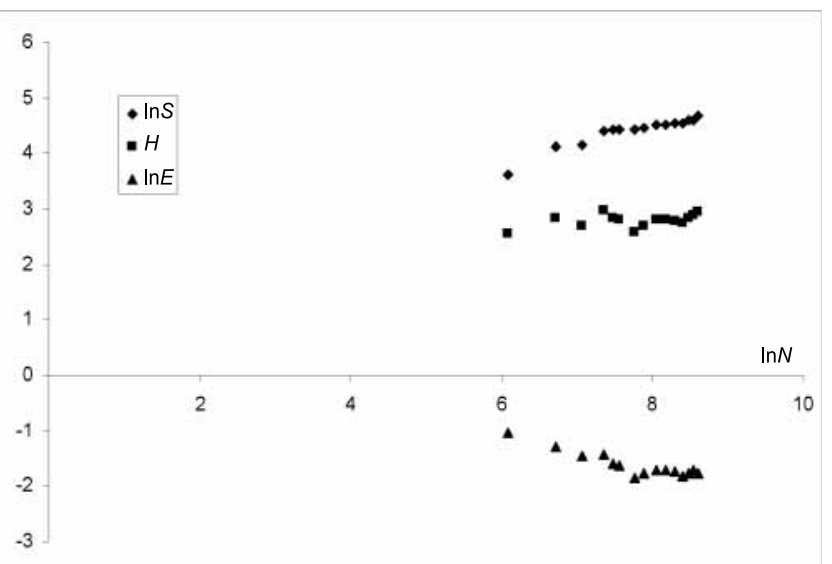

Fig. 6. Accumulated values of $\ln S, H$ and $\ln E$ against $\ln N$ for sediment samples around Nevis.
(Penicillus capitatus capitulae and Thalassia testinudum leaves in Long Haul Bay, P. capitatus capitulate in Mosquito Bay), it was within $-1 \pm 0.05$.

SHECSI analysis was used to investigate the foraminiferal population in the main cluster (thanatacoenosis) inferred from cluster analysis, which proved to have a logarithmic series population structure. However, care must be taken when attempting to reconstruct the epiphytal population from the sediment thanatacoenosis. At least $40 \%$ of the thanatacoenosis comprised allochthonous Amphistegina gibbosa, Archaias angulatus and Asterigerina carinata. Simply ignoring these allochthonous components while analysing the sediment assemblage would not yield a population structure closer to that among the epiphytal community. Whereas the thanatacoenosis yielded few planorbulinids, these dominated the biocoenosis on seagrass leaves.

The results presented here support Buzas' (2004) contention that most nearshore foraminiferal communities have a logarithmic series structure. However, these results are for epiphytal communities of the foraminiferal taxocene in an oligotrophic area where the shallow-water sediment contains few live foraminifera. Comparison between the epiphytal communities and the thanatacoenosis in the sediment indicates that, while the latter may have a logarithmic series population structure, it need not reflect the nearby epiphytal populations. In particular, the addition of allochthonous specimens, and the destruction or removal of more fragile ones, can distort the signal.

\section{ACKNOWLEDGEMENTS}

Thanks are due to Dr John Gregory for his comments, and to Dr Marty Buzas for his insightful review and his kind encouragement throughout this project. Collection of the samples was undertaken while the author was working as a high school teacher on Nevis under the auspices of Voluntary Service Overseas (VSO), a British charity that sends skilled personnel to aid in the Developing World.

\section{Manuscript received 12 December 2006 Manuscript accepted 8 January 2008}




\section{REFERENCES}

Altenbach, A.V. 1992. Short term processes and patterns in the foraminiferal response to organic flux rates. Marine Micropaleontology, 19: $119-129$.

Berryman, A.A. 1999. Principles of Population Dynamics and their Application. Stanley Thorne Publishers, Cheltenham, 243pp.

Brasier, M.D. 1975. Ecology of Recent sediment-dwelling and phytal foraminifera from the lagoons of Barbuda, West Indies. Journal of Foraminiferal Research, 5: 42-62.

Buzas, M.A. 2004. Community structure of foraminifera from two Miocene beds at Calvert Cliffs, Maryland. Journal of Foraminiferal Research, 34: 208-213.

Buzas, M.A. \& Hayek, L.-A.C. 1998. SHE analysis for biofacies identification. Journal of Foraminiferal Research, 28: 233-239.

Buzas, M.A. \& Hayek, L.-A.C. 2005. On richness and evenness within and between communities. Paleobiology, 31: 199-220.

Buzas, M.A., Smith, R.K. \& Beem, K. 1977. Ecology and systematics of foraminifera in two Thalassia habitats, Jamaica, West Indies. Smithsonian Contributions to Paleobiology, 31: 138pp.

Cushman, J.A. 1918. The Foraminifera of the Atlantic Ocean. Part 1: Astrorhizidae. United States National Museum Bulletin, 104(1): $111 \mathrm{pp}$.

Cushman, J.A. 1921. Foraminifera from the north coast of Jamaica. Proceedings of the US National Museum, 59: 47-82.

Cushman, J.A. 1922a. Shallow-water foraminifera of the Tortugas region. Carnegie Institution of Washington, 17: 3-85.

Cushman, J.A. 1922b. The Foraminifera of the Atlantic Ocean, Part 3. Textulariidae. Bulletin of the US National Museum, 104(3): 149pp.

Cushman, J.A. 1923. The Foraminifera of the Atlantic Ocean, Part 4. Lagenidae. Bulletin of the US National Museum, 104(4): 228pp.

Cushman, J.A. 1929. The Foraminifera of the Atlantic Ocean, Part 6: Miliolidae. Bulletin of the US National Museum, 104(6): 129pp.

Cushman, J.A. 1930. The foraminifera of the Atlantic Ocean, Part 7. Nonionidae, Camerinidae, Peneroplidae and Alveolinellidae. Bulletin of the US National Museum, 104(7): 79pp.

Cushman, J.A. 1931. The Foraminifera of the Atlantic Ocean, Part 8: Rotaliidae, Amphisteginidae, Calcarinidae, Cymbalopoerttidae, Globorotaliidae, Anomalinidae, Planorbulinidae, Rupertiidae, and Homotremidae. Bulletin of the US National Museum, 104(8): 179pp.

Gischler, E., Hauser, I., Hienrich, K. \& Schietel, U. 2003. Characterization of depositional environments in isolated carbonate platforms based on benthic foraminifera, Belize, Central America. Palaios, 18: 236-255.

Hallock, P., Lidz, B., Cockey-Burkhard, E.E. \& Donnelly, K.B. 2003. Foraminifera as bioindicators in coral reef assessment and monitoring: The FORAM Index. Environmental Monitoring and Assessment, 81: $221-238$.

Hayek, L.-A.C. \& Buzas, M.A. 1997. Surveying Natural Populations. Columbia University Press, New York, 562pp.

Hurlbert, S.J. 1984. Pseudoreplication and the design of ecological experiments. Ecological Monographs, 54: 187-211.

Hutchinson, G.E. 1976. An Introduction to Population Ecology. Yale University Press, New Haven, 260pp.

Jaksic, M.F. 1981. Use and abuse of the term 'guild' in ecological studies. Oikos, 37: 397-400.

Langer, M. 1993. Epiphytic Foraminifera. Marine Micropaleontology, 20: $235-265$.

Li, C., Jones, B. \& Blanchon, P. 1997. Lagoon-shelf sediment exchange during storms: Evidence from Foraminiferal tracers, Grand Cayman. Journal of Sedimentary Research, 67: 17-25.

Magurran, A.E. 1988. Ecological Diversity and its Measurement. Chapman \& Hall, London, 179pp.

Magurran, A.E. 2003. Measuring Biological Diversity. Blackwell Publishing, Cambridge, 260pp.
Martin, R.E. 1986. Habitat and distribution of the foraminifer Archaias angulatus (Fichtel and Moll) (Miliolina, Soritidae), northern Florida Keys. Journal of Foraminiferal Research, 16: 201-206.

Martin, R.E. \& Wright, R.C. 1988. Information loss in the transition from life to death assemblages of foraminifera in back-reef environments, Key Largo, Florida. Journal of Paleontology, 62: 399-410.

Orbigny, A.C.d' 1839. Foraminifères. In: de la Sagra, M.R. (Ed.), Histoire Physique, Politique et Naturelle de l'Ile de Cuba. Arthus Bertrand, Paris, 224pp.

Ribes, T., Salvadó, H.J.R. \& del Pilar Gracia, A. 2000. Foraminiferal colonization on artificial seagrass leaves. Journal of Foraminiferal Research, 30: 192-201.

Root, R.B. 1967. The niche exploitation pattern of the blue-grey gnat-catcher. Ecological Monographs, 37: 317-350.

Schnitker, D. 1971. Distribution of foraminifera on the North Carolina continental shelf. Tulane Studies in Geology and Paleontology, $\mathbf{8}$ : $169-215$.

Scott, D.B., Medioli, F.S. \& Schafer, C.T. 2001. Monitoring of Coastal Environments using Foraminifera and Thecamoebian Indicators. Cambridge University Press, Cambridge, 192pp.

Stapel, J., Nijboer, R. \& Philipsen, B. 1996. Initial estimates of the export of leaf litter from a seagrass bed in the Spermonde Archipelago, South Sulawesi, Indonesia. In: Kuo, J. (Ed.), Seagrass Biology: Proceedings of an International Workshop, Rottnest island, Western Australia. Faculty of Sciences, University of Western Australia, Nedlands, Australia, 155-162.

Steinker, D.C. \& Clem, K.V. 1984. Some near-shore foraminiferal assemblages from phytal and bottom sediments, Bermuda. The Compass, 61: 98-115.

Todd, R. \& Low, D. 1976. Smaller foraminifera from deep wells on Puerto Rico and St. Croix. U.S. Geological Survey Professional Paper, 863: $1-32$.

Walton, W.R. 1952. Techniques for recognition of living foraminifera. Contributions to the Cushman Foundation for Foraminiferal Research, 3: $56-60$.

Waszczak, R.F. \& Steinker, D.C. 1978. Paleoenvironmental and paleoecologic implications of recent foraminiferan distribution patterns in the lower Florida Keys. Miami Geological Society Memoir, 3: 203-225.

Wilson, B. 1998. Epiphytal Foraminiferal Assemblages on the Leaves of the Seagrasses Thalassia testudinum and Syringodium filiforme. Caribbean Journal of Science, 34: 131-132.

Wilson, B. 2000. Benthonic foraminifera as a tool in environmental quality control: Two Caribbean examples. Geological Society of Trinidad and Tobago Conference and Exhibition, 10-13 July, Port-ofSpain, Trinidad. CD-ROM. Geological Society of Trinidad and Tobago, Port of Spain, Trinidad.

Wilson, B. 2006a. The environmental significance of some microscopic organisms around Nevis, West Indies. West Indian Journal of Engineering, 28: 53-64.

Wilson, B. 2006b. The environmental significance of Archaias angulatus (Miliolida, Foraminifera) in sediments around Nevis, West Indies. Caribbean Journal of Science, 42: 20-23.

Wilson, B. 2006c. Guilds among epiphytal foraminifera on fibrous substrates, Nevis, West Indies. Marine Micropaleontology, 63: 1-18.

Wilson, B. \& Dawe, R.A. 2006. Detecting seasonality using time series analysis: Comparing foraminiferal population dynamics with rainfall data. Journal of Foraminiferal Research, 36: 108-115.

Wilson, B. \& Ramsook, A. 2007. Population densities and diversities of epiphytal foraminifera on nearshore substrates, Nevis, West Indies. Journal of Foraminiferal Research, 37: 213-222.

Zieman, J.C. \& Zieman, R.T. 1989. The ecology of the seagrass meadows of the west coast of Florida. Biological Report of the US Department of the Interior, 35: 155pp. 